\title{
Intonational Patterns of Nonverbal Vocalizations in People With Dementia
}

Christina Samuelsson and Lars-Christer Hydén

\section{Linköping University Post Print}

N.B.: When citing this work, cite the original article.

Original Publication:

Christina Samuelsson and Lars-Christer Hydén, Intonational Patterns of Nonverbal Vocalizations in People With Dementia, 2011, American Journal of Alzheimer's Disease and Other Dementia, (26), 7, 563-572.

http://dx.doi.org/10.1177/1533317511428152

Copyright: SAGE Publications (UK and US)

http://www.uk.sagepub.com/

Postprint available at: Linköping University Electronic Press

http://urn.kb.se/resolve?urn=urn:nbn:se:liu:diva-74170 
Intonational Patterns of Non-verbal Vocalizations in People with Dementia 


\begin{abstract}
Non-verbal vocalizations in dementia are important clinically since they generally have been regarded as disruptive behavior that is disturbing. The aim of the present study is to describe the interactional pattern, including the prosodic package, of non-verbal vocalizations in a participant in a late stage of dementia. The acoustic analysis show that the vocalizations do not differ significantly from the verbal utterances regarding mean fundamental frequency or pitch range. The mean fundamental frequency, F0, of the utterances from Anna was significantly higher than the mean F0 from the other elderly participants. The analysis demonstrates that there is a singing-like type of vocalizations that does not resemble the previously described patterns of non-verbal vocalizations. This pattern of the non-verbal vocalization does not resemble the intonation of Anna's verbal utterances. The other participants perceive Anna's vocalizations as potentially meaningful turns. Non-verbal vocalizations in clinical settings should be taken as communicative contributions.
\end{abstract}




\section{Introduction}

Pragmatic abilities are known to be impaired in people with dementia ${ }^{1}$. In late stages of dementia, noise-making or disruptive vocalizations are rather common ${ }^{2}$. Non-verbal vocalizations are important clinically since they generally have been regarded as an a-social, disruptive, behavior that is disturbing to caregivers and patients, and are often interpreted as a sign of discomfort from the people with dementia ${ }^{3,4}$. There are different theoretical frameworks explaining these behaviors. They may be interpreted as a direct consequence of the dementia itself, as an expression of unmet needs, as an expression of non-communicable feelings and experiences, or as an increased vulnerability to environmental factors 5,4 .

Given recent years research about the social abilities of persons with Alzheimer's Disease, $\mathrm{AD},\left(\mathrm{cf}^{6}\right)^{6}$ it is interesting to investigate non-verbal vocalizations not as isolated phenomena but as part of a specific interactional context and particularly in what ways - if any - the interactional context affects the nature of the non-verbal vocalizations. As a consequence of the attempt to introduce a social perspective on noise-making and disruptive vocalization we will use the term verbal and non-verbal vocalizations (VNVV) as a more neutral and appropriate term ${ }^{7}$.

\section{Verbal and non-verbal vocalization in dementia}

Language impairment is a regular feature in dementia, while language abilities are quite well preserved in normal aging ${ }^{8,9,10}$. Language problems vary, both regarding severity and characteristics, in relation to the type and degree of dementia. However, language 
impairment is associated with behavior problems in dementia also when severity of dementia is controlled for ${ }^{11}$.

Language impairment in dementia is not as well defined as aphasia acquired from focal brain lesions, but includes word finding problems, syntactic problems and finally also a disturbance of pragmatic functions ${ }^{12}$. The linguistic problems are related to cognitive impairments in especially the episodic and semantic memory systems together with declining executive functions (cf. $\left.{ }^{13}\right)$.

In late stages of dementia, patients may be mute or restricted to palilalia or echolalia. There are also cases of abnormal laughter-like vocalizations in progressive aphasia ${ }^{14}$. These vocalizations did not show contextual sensitivity but occurred as an automatic output replacing speech.

It has been found that among all elderly patients between 48 and 55 percent of those patients that engage in non-verbal vocalizations suffer from Alzheimer-type dementia and 30 percent from vascular dementia; while between 12 and 30 percent of patients diagnosed with some kind of dementia scream (for a review of research, $\operatorname{see}^{4}$ ). It has also been found that nonverbal vocalizations occurred mostly in the evening, when the patients were alone, restrained, in the bathroom or receiving care ${ }^{4}$. 
In a study by Nagaratnam, Patel and Whelan ${ }^{15}$, four categories of vocalizations (noisemaking) were identified; persistent screaming, perseverative vocalization, continous chattering, muttering, singing or humming and swearing, grunting and bizarre noise-making. This categorization was based on medical records from twelve patients with Alzheimer's disease and vascular dementia. The persistent screaming was described as shrieking, crying or screaming. The perseverative vocalization was described as stereotyped utterances, e.g. continuous counting. The continuous chattering, muttering, singing or humming, was described as constant unintelligible muttering or repeatedly speaking of the same topic and the swearing, grunting and bizarre noise-making was described as continuously swearing and shouting obscenities. All four behaviors occurred in association to agitation ${ }^{15}$.

Ryan and his colleagues ${ }^{16}$ presented a typology of different kinds of what they termed 'nonverbal and vocal disruptive behaviors': (1) noise-making that appears purposeless and preservative; (2) noise-making which is a response to the environment; (3) noise-making which elicits a response from the environment; (4) 'chatterbox' noise-making; (5) noisemaking due to deafness, and (6) other noise-making. In contrast to this typology CohenMansfield - who together with her research group probably has spent most time and effort on this phenomenon - suggested a dimensional typology ${ }^{3}$. Their typology of vocalizations includes four dimensions: (1) type of sound, (2) purpose of the sound, (3) response to the environment, and (4) levels of disruptiveness.

Interestingly, very few of these researchers have suggested non-verbal vocalizations among people with dementia being part of social interaction or having a clear social value besides being disruptive. In contrast, researchers interested in the non-verbal vocalizations of infants 
argue that early non-cry vocalizations of infants are clearly social signals ${ }^{17}$. Caregivers spontaneously respond to $30-50 \%$ of these vocalizations ${ }^{18}$. Pre-linguistic babbling often seems remarkably speech-like since it seems to have adult-like prosody. It has been demonstrated that infants produce adult-like stress patterns and that they used variation in pitch, intensity and duration in an adult-like manner ${ }^{19}$. There are several studies on how caregivers respond to vocalizations of infants and the importance for social and interactional development is emphasized ${ }^{20,21,18}$.

The study of the acoustic characteristics of non-verbal vocalizations in elderly has to date been very limited. A study by Cohen-Mansfield, Werner, Hammerschmidt and Newman ${ }^{22}$, is an important exception. They performed acoustic analysis of temporal aspects and frequency of vocalizations, corresponding to rhythm and melody (intonation) of vocalizations, from 26 nursing home residents. Their results demonstrated that the vocalizations of agitated nursing home residents were short in duration and in high fundamental frequency. They did not find any indicators that could differentiate between types of dementia. However, no analysis of the interactional consequences of the non-verbal vocalization was made in the study ${ }^{22}$.

In the following, focus will be on the prosodic aspects of non-verbal vocalizations, especially in relation to the organization of the ongoing interaction. This approach is based on previous research has focused on pragmatic ability in people with dementia and the pragmatic impairment is viewed as a major source of communicative disruptions. With an interactional approach, the co-construction of understanding becomes central and well functioning sequences are identified ${ }^{1}$. The aim of the present study is to describe the interactional pattern, including the prosodic packages, of non-verbal vocalizations in a 
participant in a late stage of dementia. Vocalization data has been analyzed by means of acoustic measurements alongside the sequential analysis, allowing for the acoustic features, mainly mean fundamental frequency and pitch contours, to be related to the sequential aspects of the analysis. In the previous literature, analyses are mainly made of either the person with dementia or the caregiver. Thus, relating them to each other may add knowledge on how participants in interaction are influenced and influences each other also when one of them communicates with non-verbal vocalizations.

\section{Methods and materials}

In the following the non-verbal vocalizations of one person in two different situations will be used for analysis. In this sense, it is a case study aiming at delineating certain basic aspects of vocalizations in relation to social interaction. The intention is not to generalize the findings to the whole population of persons suffering from Alzheimer's dementia, AD, or a subset of these, but rather to show the possibility of the suggested methodological and analytical framework, and also to point to certain implications of the approach concerning the understanding of verbal and non-verbal vocalizations.

The examples used are part of a video recorded material consisting of several hundred hours of recording from a nursing home for persons with $\mathrm{AD}$. In the material interaction between staff and inhabitants, between persons with dementia without any staff present, are found. In this material a small number of instances involving non-verbal vocalizations was identified and used for further analysis. (For further descriptions of this material see ${ }^{23}$.) The chosen key portions of the material were the only parts where the non-verbal vocalizations were present and possible to analyze. 


\section{Participants}

The main participant in the present study is a woman, here called Anna. She is about 85 years old, has had AD for many years and is approaching the third and final stage of this disease. She has profound problems with speech and language use in general and also with her hearing. She is very slow in her movements and has problems coordinating them, for instance when she is eating. Sometimes she says something in a weak voice. More often she has problems producing words and instead vocalizes sounds. Her communication with others is very limited, and she mainly communicates with non-verbal vocalizations. In the present data, two other residents, $\mathrm{B}$ and $\mathrm{C}$, in the nursing home participate in the interaction. These two ladies are also diagnosed with $\mathrm{AD}$, although in a less advanced stage as compared to Anna. The two ladies mainly interact with each other, but they also orients to Anna's contributions in the interaction. The fourth participant in the present study is the researcher, $\mathrm{R}$, who contributes to the interaction on some occasions. The researcher stayed as an observer in the nursing home during the months the data were collected.

\section{Data}

In the following two episodes will be used for analysis. Both episodes evolve around the dinner table at the nursing home. In the first episode some of the participantstogether with a nurse are having lunch. In the second episode, recorded at couple of days later, the three guests described above, are lingering around the table after breakfast.

The episodes are part of video recordings covering longer stretches of time and also of an extended ethnographic presence for almost six months. The ethnographic fieldwork makes it 
possible to understand some of problems persons suffering from $\mathrm{AD}$ have as part of the specific activity ecology of the nursing home. Behaviors, utterances and actions that may appear as classical symptoms of AD become at least somewhat more understandable if they are seen as part of a specific context (for instance ${ }^{23}$ for further information about the material).

\section{Acoustic Analysis}

The acoustic analysis was made both of verbal and non-verbal material. To measure the mean fundamental frequency, F0, as a whole for each participant, the mean F0 for each utterance was measured using the Praat Software ${ }^{24}$. The mean F0 was then calculated by adding the values from each utterance and dividing the sum with the total number of utterances. To obtain the pitch range, min was measured and subtracted from the measured max F0 in utterance by utterance for each participant separately. The mean pitch range was then calculated in the same way as the mean F0. In order to check for statistically significant differences, both between Anna and the other participants and between Anna's verbal and non-verbal vocalizations, Mann-Whitney U-tests performed.

Sequential Prosodic Analysis 
In the present paper, a detailed sequential analysis was carried out in order to assess the structural and the intonational features of the participants, with special focus on Anna. A sequential analysis of interaction can be made in different ways. In a few earlier studies, Conversation Analytic methodology (CA) has been applied to analyses of conversation involving people with dementia ${ }^{1,25}$. In CA, understanding and meaning are viewed as collaboratively constructed by participants in interaction and every utterance is analyzed in relation to the context in which it occurs. The present data are analyzed sequentially in a CA-informed way, with a special focus on prosody.

\section{Results and Analysis}

In the following, the acoustic properties of non-verbal vocalizations from one person are used for analysis. Moreover, interactional aspects of the vocalizations will be taken into account.

\section{Acoustic analysis}

The participant, Anna, produces verbal speech with a varying degree of intelligibility in addition to her non-verbal vocalizations. From an overall perspective the non-verbal vocalizations do not differ significantly $(\mathrm{p}=0.2)$ from the verbal utterances regarding mean fundamental frequency or pitch range, (figure 1).

However, the mean fundamental frequency of the verbal utterances from Anna was significantly lower than the mean F0 $(\mathrm{p}<0.0001)$ from the other elderly participants (figure 2). 


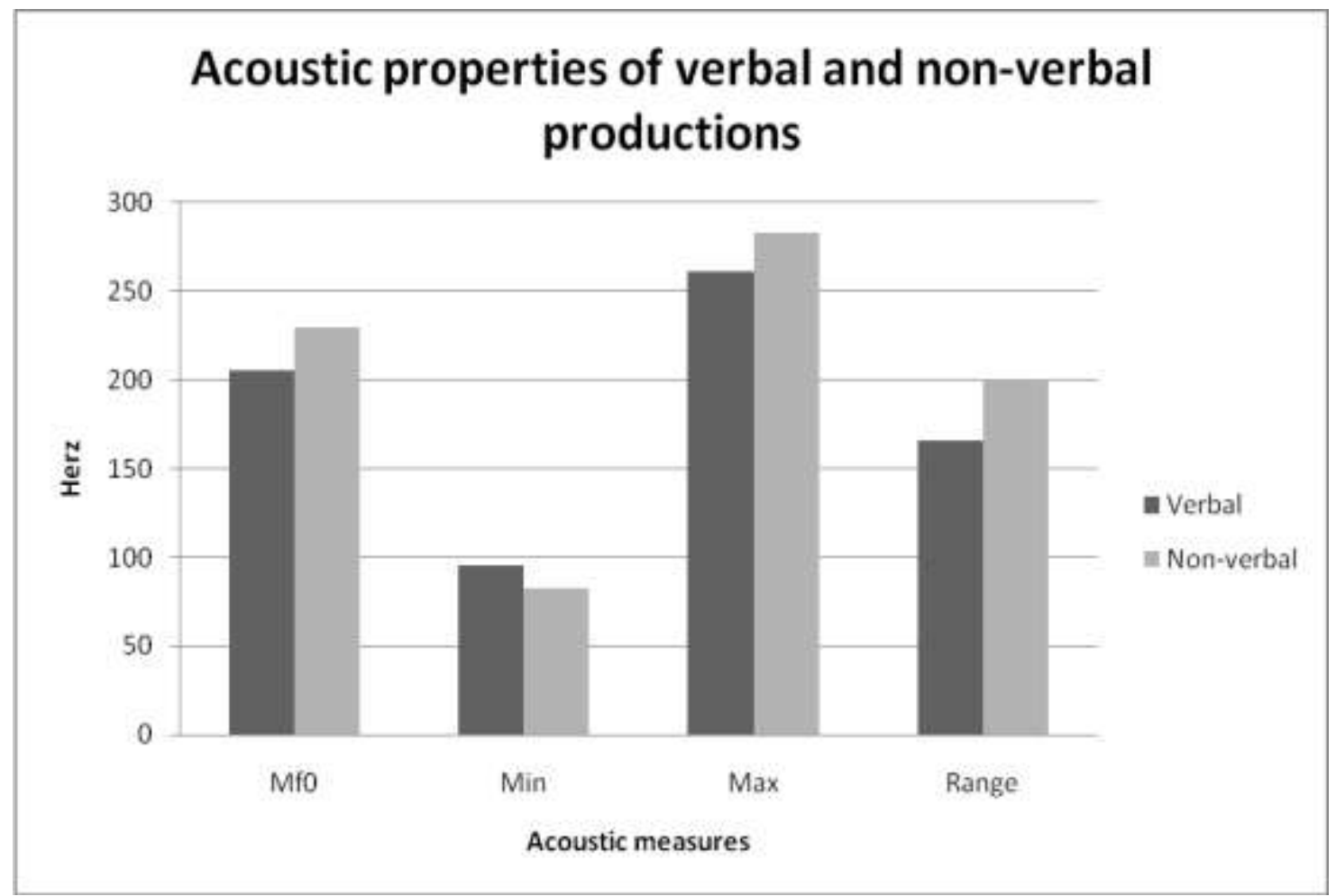

Figure 1. Acoustic properties of Anna's verbal utterances in relation to the acoustic properties of her non-verbal vocalizations. Mf0=Mean fundamental frequency, Min=lowest fundamental frequency, Max=highest fundamental frequency, Range= pitch range (from the lowest to the highest measured fundamental frequency).

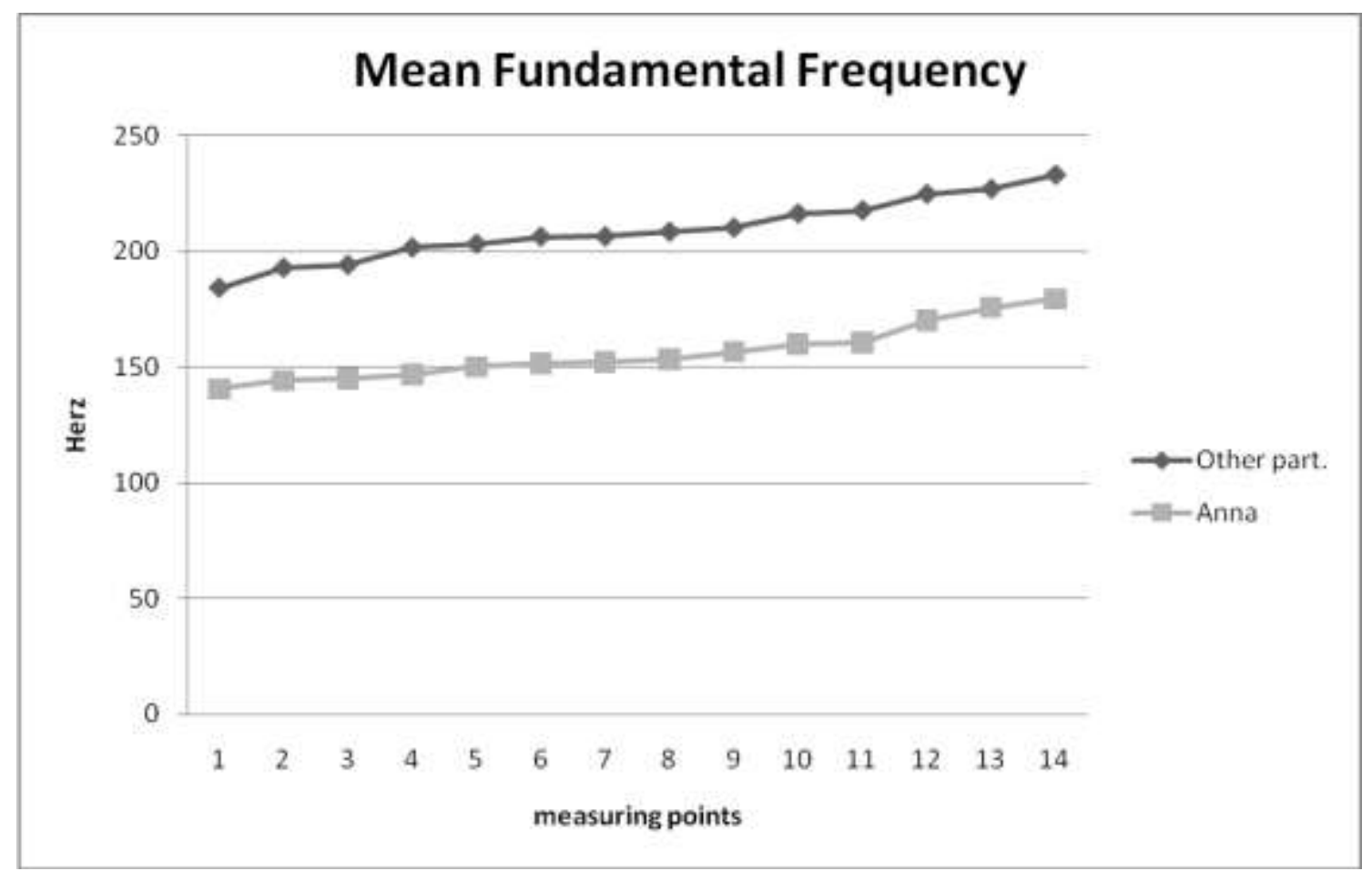

Figure 2. Anna's mean fundamental frequency in relation to the mean fundamental frequency of the other elderly participants. 
The mean pitch range of the other participants was significantly higher $(\mathrm{p}<0.0001)$ than the pitch range of Anna. In conclusion, this means that Anna's verbal utterances were produced in low pitch with rather flat intonational contour (figure 3).

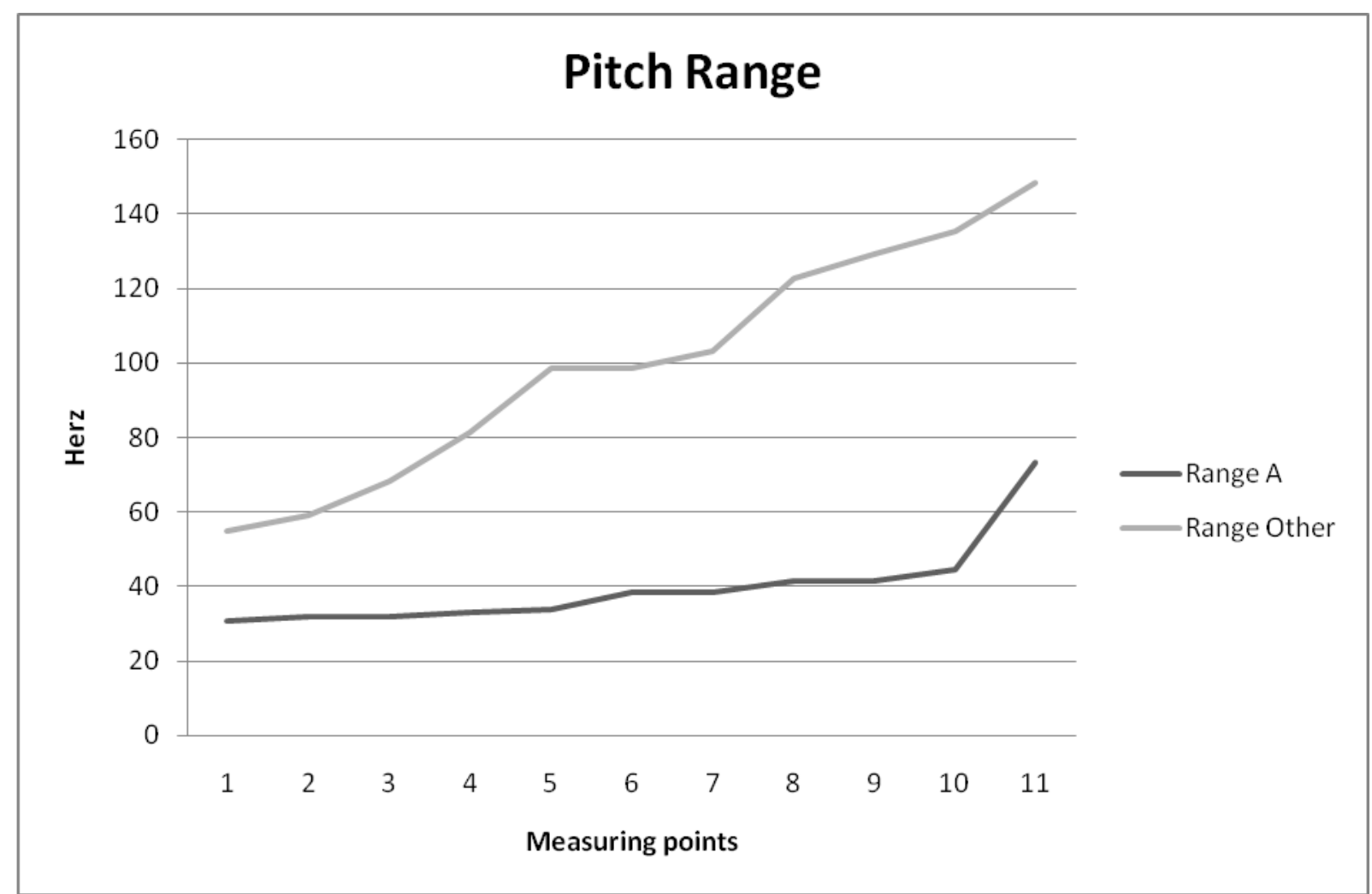

Figure 3. Pitch range of Anna's verbal utterances in relation to the pitch range of the other elderly participants.

Detailed analysis of the non-verbal vocalizations reveals three things. (1) A stereotyped prosodic pattern distinguishing the nonverbal from the verbal utterances, demonstrated by the acoustic measurements described above. (2) Two seemingly different pitch patterns of non-verbal vocalizations also appear; one singing-like pattern and one flatter pattern as shown in the sequential analysis below. (3) There are also indications of a particular prosodic patterns in Anna's verbal utterances signaling anger, as shown in example 9 below where Anna uses a very distinct prosodic pattern with lower mean fundamental frequency and larger pitch range than her previous verbal utterances. 
Sequential Prosodic Analysis

The included recordings were transcribed in accordance with the demands of CA, which means that a great variety of detail was taken into account, including pauses, hesitations and overlaps etc. In the sequential analysis, prosodic features are illustrated by F0-curves of each contribution to the interactions, in accordance with the pioneering work by Local and Wells ${ }^{26,27}$

From an overall perspective, the sequential prosodic analysis demonstrates that Anna's nonverbal vocalizations do interactional jobs. The analysis also revealed that the other participants orient to the vocalizations in different ways. In almost all instances of nonverbal vocalizations, Anna looks at the other participants, indicating that her basic pragmatic competence is preserved.

\section{Example 1}

This first example illustrates the typical, most frequent pitch pattern of the non-verbal vocalizations from Anna. These vocalizations are produced repetitively and they are perceived as a monotonous singing. The same intonational pattern is repeated very often. 
$\mathrm{A}=$ Anna

A: lalalalalala<lalala>lalalalalalalala

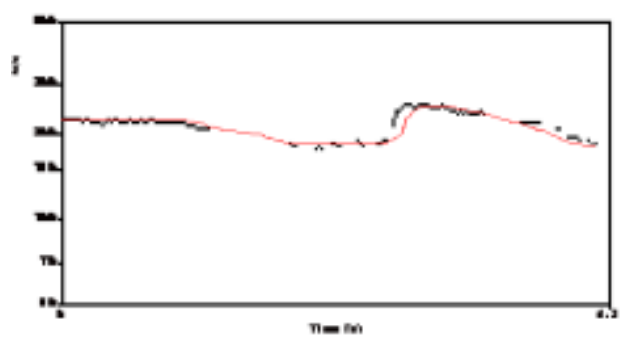

In the above example the typical wave-like pitch-pattern is shown, where the pitch starts rather high, around $225 \mathrm{~Hz}$, rises up to about $275 \mathrm{~Hz}$ and the goes down again. The stereotyped pitch-movement up and down resembles singing more than talking and it is repeated every time the singing-like non-verbal vocalizations occurs, see also example 2 . The resemblance to singing is also enhanced by the fact that most of these vocalizations are articulated with the syllable "la", which is the most frequently used syllable for humming in Swedish

Example 2

$\mathrm{A}=\mathrm{Anna}, \mathrm{B}=$ other resident

1. A:lalalalalalalalallala<lalalalalalalalalalal>

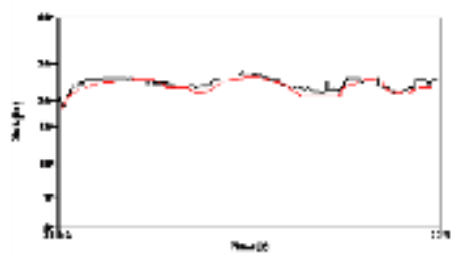

2. B :

<de vante mycket sång >

<that was not much song> 


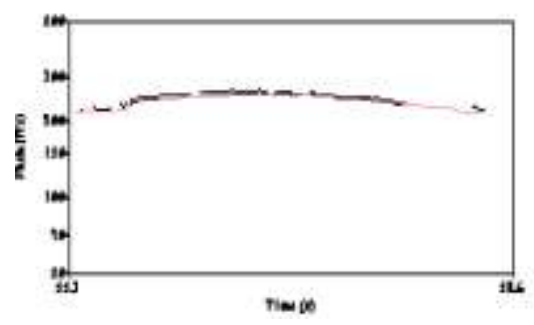

4. B: <taget va ho säger>

<thing what she says>

This stereotyped prosodic pattern being similar to singing is also observed and oriented to by another participant, $\mathrm{B}$, which is illustrated in by the comment on line two, where she indicate that the singing is rather bad. The following three examples also demonstrate that the other participants orientate to the pattern as singing-like. Nevertheless, the vocalizations, which seem to be Anna's spontaneous way of expressing herself, do an interactional job since they make the other participants address Anna in interaction.

\section{Example 3}

$\mathrm{A}=\mathrm{Ann} \mathrm{a}, \mathrm{B}=$ other resident

1. A: aaaajajajajajajajaj

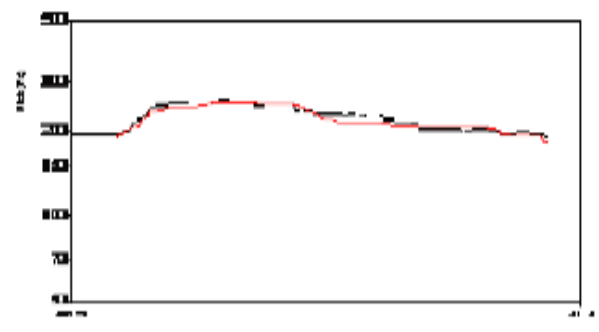




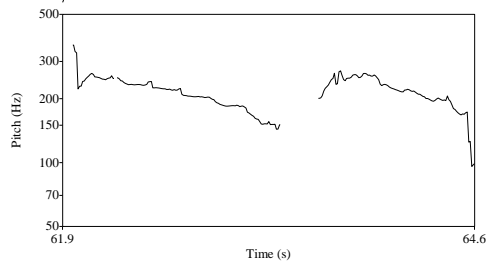

In line 2, B imitates in a slightly exaggerated way the prosodic package used by Anna for the non-verbal vocalizations. This imitation is not responded to by any of the participants. Participant B also makes several meta comments on the vocalizations from Anna, demonstrating that she orients to them as some kind of singing, however not resembling to any known song, see examples 4 and 5.

\section{Example 4}

$\mathrm{A}=$ Anna, $\mathrm{R}=$ researcher, $\mathrm{B}=$ other resident, $\mathrm{P}=$ pause

1. A: alala(.)alala:lal=

2. R: =vava :
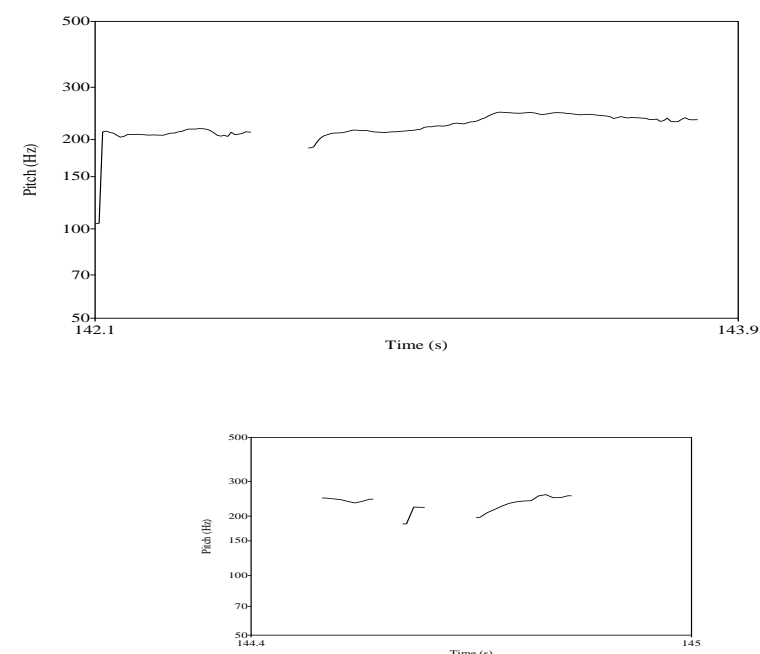

what 
3. B: ä dä en sång dä (0.6) dä vante så värst

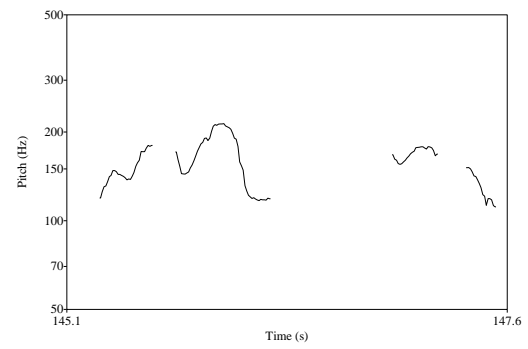

Is that a song it was not very good

4. P: 2.3

In line 1, Anna keeps on her singing-like vocalization, which is followed by a request for clarification by the participating researcher in line 2 . In line $3, \mathrm{~B}$ comments on Anna's contribution by asking if it is a song, and when this is not answered by Anna, B continues with commenting that it was not a very good song. This turn closes the sequence and is followed by a pause. In example five, B also asks a question about the song.

\section{Example 5}

$\mathrm{A}=\mathrm{Anna}, \mathrm{B}=$ other resident

1. A: alalalalalalalalala

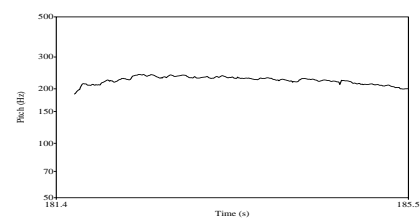

2. B: va heter den sången (0.6) lololololololol

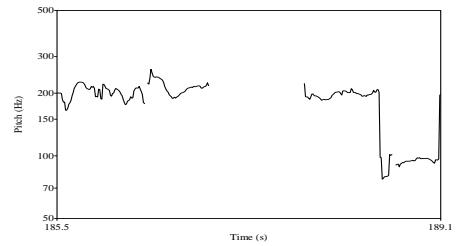

What is the name of that song 
3. A: lalalalalalalala<lalala>

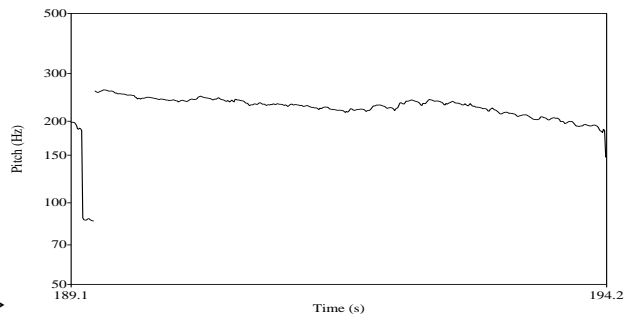

Anna is making her singing-like vocalization in line one and in line $2, \mathrm{~B}$ asks about the name of the song. This question does not get any answer from Anna, and after a short pause B makes an imitation of the intonational pattern of Anna's vocalization. Anna orients to this imitation by continuing her vocalization in the same manner, line 3 . This kind of stereotyped singing-like vocalization does not correspond to any previously described non-verbal vocalizations $^{15,22}$.

The other repeated pitch pattern of the non-verbal vocalizations is more monotonous than Anna's pattern previously describedabove. Anna also uses this pattern less frequently, and sometimes she articulates it with a less singing-like syllable.

\section{Example 6}

$\mathrm{A}=\mathrm{Anna}, \mathrm{CG}=$ caregiver
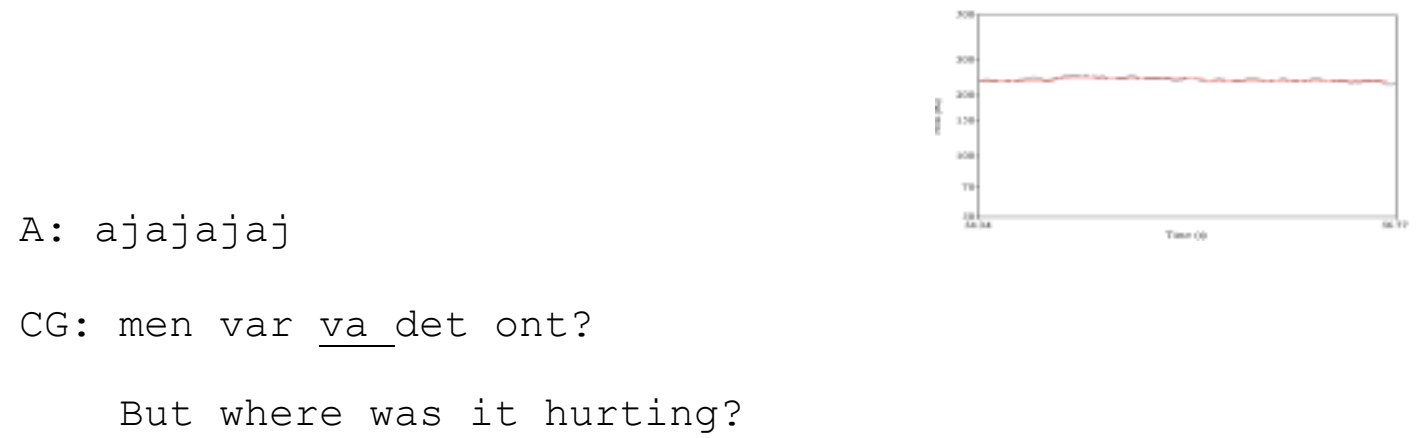
In example six the syllable "aj" is produced at a rather high pitch, about $240 \mathrm{~Hz}$, with very little variation. This utterance/vocalization does not get any response from the other elderly participants, but after a while someone working at the nursing home, CG, steps up and asks Anna if she is feeling alright.

There are also instances where the syllable "la" is used, and this pattern is commented on, but not with any reference to singing.

\section{Example 7}

$\mathrm{A}=\mathrm{Anna}, \mathrm{B}=$ other resident, $\mathrm{C}=$ second other resident, $\mathrm{P}=$ pause

1. C: <de må>ste de ku<xxxxxxxxxxx>

2. A :

3.P: $4.2((\operatorname{smäll}))$

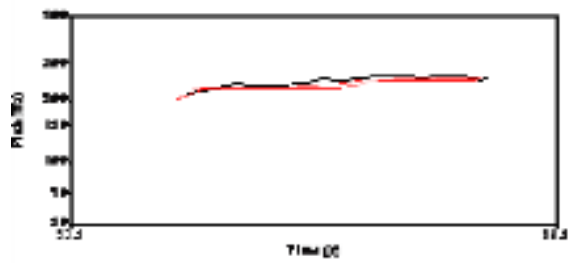

5. B: de ä så ho håller på nu då

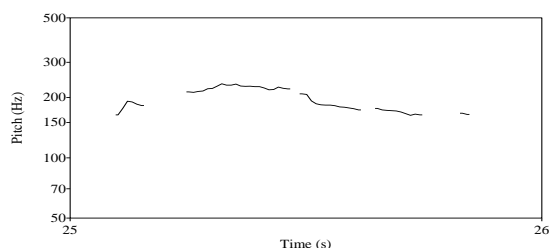

That is how she goes on now then 


\section{A: jaja}

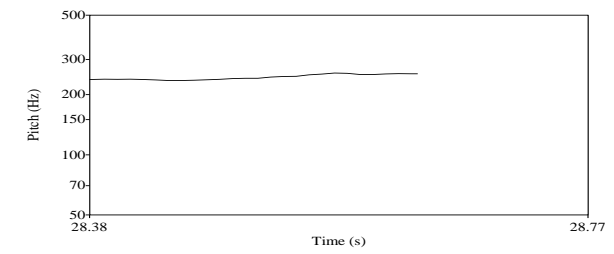

Yes yes

In line 2, Anna makes a non-verbal vocalization ending with a prolonged "a:". This vocalizations does not get any response. In line 4 , the pattern is repeated. B comments the vocalization in line 5, however not addressed directly towards Anna even though it gets a verbal response from Anna in line 6. Also in this example Anna's vocalizations are produced with a high pitch, above $250 \mathrm{~Hz}$. These vocalizations are also rather short in duration and the pattern with high pitch and short durations is in accordance with the pattern previously described by Cohen Mansfield et al. ${ }^{22}$.

On several occasions, Anna's non-verbal vocalizations are interrupted by responses from the other participants, most often the participating researcher. In these sequences, Anna responds with verbal utterances with a varying degree of intelligibility. The intonational pattern of the verbal utterances are less stereotyped than the non-verbal vocalizations and their mean fundamental frequency is slightly lower (although not significantly). 


\section{Example 8}

$\mathrm{A}=\mathrm{Anna}, \mathrm{B}=$ other resident, $\mathrm{R}=$ researcher, $\mathrm{P}=$ pause

1. A: <nnnnnnnnnnnnnnnnnnnnnnn>nnnnnnnnnnnnnnn

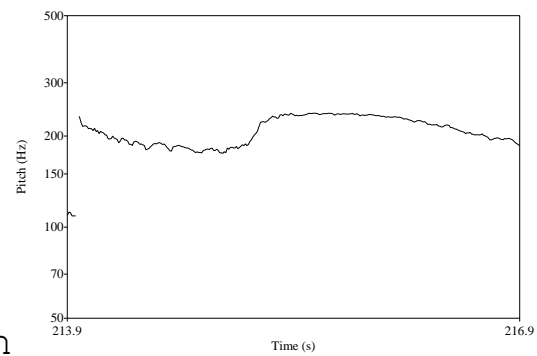

2. B: <liknar en karl ur sidan>

<looks like a man from the side>

3. R: va e de som e så tråkit o jobbit

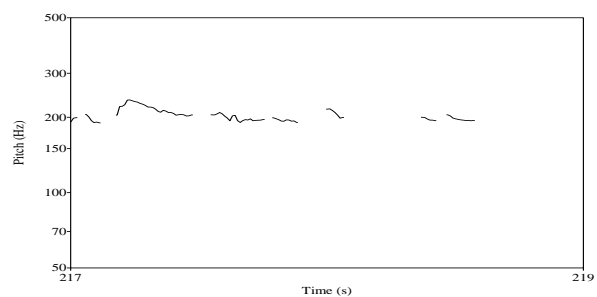

What is so boring and hard

4. A: mm de saker (.) vem e de?

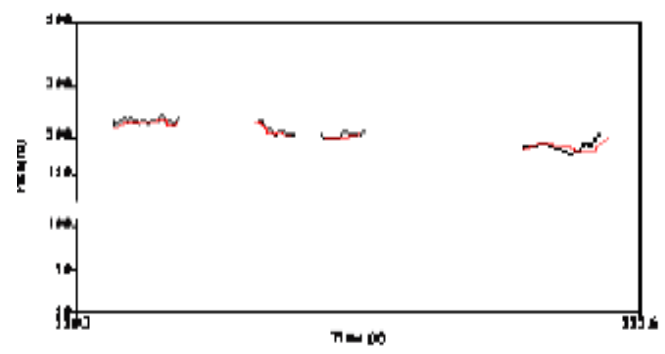

It is things who is that?

5. P: 2.5 


\section{R: vem ja är? \\ Who I am?}

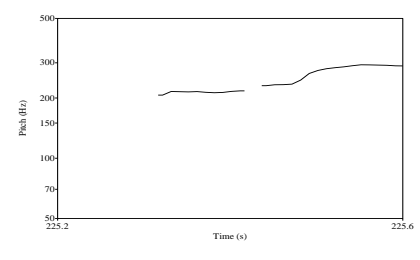

Anna keeps making non-verbal singing-like vocalizations in line 1 in overlap with a contribution from $\mathrm{B}$. The participating researcher, $\mathrm{R}$, asks a question in line 3 and Anna responds verbally and initiates a new topic in line 4 . The pitch contour in this utterance does not resemble the singing-like pattern demonstrated in examples 1-3, the fundamental frequency is slightly lower as well as the pitch range. By asking the question about boredom in line 3 , the participating researcher offers an account for the meaning of the non-verbal vocalization. The need for candidate understandings demonstrate that the difficulties of understanding is also a joint problem of interaction. This might be an expression of a "vicarious voice" 28 , from the researcher for Anna and in this example this contribution interrupts the singing-like vocalization and elicits verbal communication.

In one sequence shown in example nine, Anna demonstrates anger in a verbal utterance, mainly through a prominent prosodic package.

\section{Example 9}

$\mathrm{A}=\mathrm{Anna}, \mathrm{CG}=$ caregiver, $\mathrm{C}=$ second other resident, $\mathrm{P}=$ pause 
1.A: ajajajajajajajajajajajajajaj

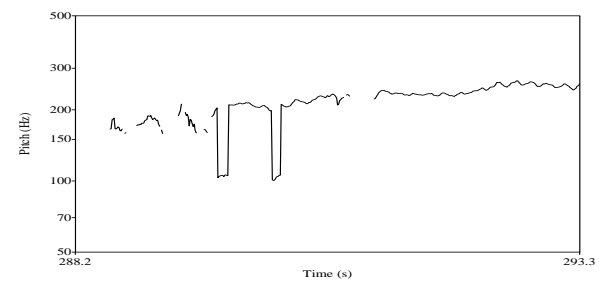

2. CG: va de ont?

Did it hurt?

3. C: men nu får du vara tyst annars så kan vi inte vara inne här But now you have to be quiet otherwise we can't stay in here

4. P: 1.7

5. C: nu ska du äta här o vara tyst en stund

Now you should eat and be quiet for a while

6. A: va e va ja lololo

7. C: ja här har du din smörgås

Yes here you have your sandwich

8. A: ja har inga vennaninan ((sounds angry))

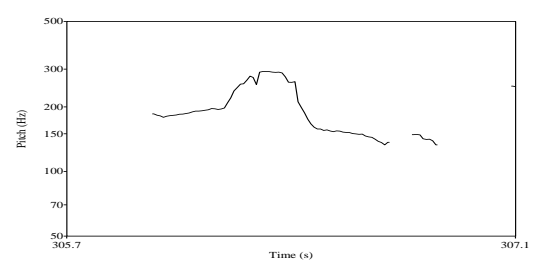

I do not have any friendeses

9. C: den ä så go så

It is soo good

In line 1, Anna is making a non-verbal vocalization and in line 2 another participant orients to this as an expression of pain, probably depending on the syllable "aj" that Anna uses in this example. This contribution is not responded to by Anna, and participant C, who is well acquainted with Anna, tells Anna to stop vocalizing in a rather soliciting way (line 3 and 5). 
Anna responds verbally but unintelligibly in line 6 and in line $7 \mathrm{C}$ tells her to eat her sandwich. In line 8 Anna produces a very distinct phrase with lower mean fundamental frequency and larger pitch range than her previous verbal utterances. $\mathrm{C}$ orients to this expression of anger by commenting that the sandwich is good.

In sum, the sequential analysis demonstrates that the most frequent pattern of Anna's nonverbal vocalizations follow a singing-like pitch contour, which is also oriented to as singing by the other participants in the interaction. Nevertheless, also the singing-like contributions make the other participants address Anna and thereby give her some attention. The analysis also reveals another, flatter pattern resembling to the previously described acoustic patterns $^{22}$. In addition, it is demonstrated that the non-verbal vocalizations may be interrupted by contributions by the other participants. Furthermore, Anna demonstrates her interactional competence by expressing anger in an adequate and intelligible way. It also becomes clear that the other participants perceive Anna's vocalizations as distinct sound patterns, which they can imitate (cf. example 5 above), and also a potentially meaningful $\operatorname{turn}^{7}$.

\section{Concluding discussion}

It is clear that the participant in the present case study has severe language problems, sometimes resulting in for instance non-verbal vocalization. In the present analysis, it is demonstrated that there is a singing-like type of non-verbal vocalizations that does not resemble the previously described patterns of non-verbal vocalizations ${ }^{22,15}$. The singing-like intonational pattern of the non-verbal vocalization does not resemble the intonation of Anna's verbal utterances, which adds to the notion that this is a routinized pattern connected 
to the non-verbal activity. In previous research it has also been argued that non-verbal vocalizations are non-social and disruptive $e^{3,4}$, but in the present data, it is also demonstrated that the participants orient to the non-verbal vocalizations in an interactional way.

The intonational pattern of Anna's verbal utterances is different from the prosodic package of the non-verbal vocalizations. It also differs to some extent from the other elderly participants, so that it has an overall lower mean fundamental frequency and less pitch variation. On one occasion Anna signals anger (example 9) and in this example Anna is able to use prosodic features in order to signal emotional state. This examplealso demonstrates that Anna orients to negative and condescending comments with anger. This is an important finding that may have been overlooked if only the structural aspects of language had been taken into account. This is also an important clinical finding, since the prosody of unintelligible verbal utterance is rarely made.

The laughter-like vocalizations described by Rohrer and colleagues ${ }^{14}$ is claimed to be replacing speech, which also seems to be the case of the singing-like vocalizations in the present study. However, acoustic analysis of laughter-like vocalizations revealed that they were dys-rhythmic and fragmentary indicating motor disorganization. In contrast to this, the singing-like vocalizations described here is very rhythmic and recurrent, which does not indicate any motor disorganization.

There are obvious parallels between vocalizations in infants and non-verbal vocalizations in people with dementia, mainly regarding the acoustic features, such as high pitch and large 
pitch variation. In previous research it has been demonstrated that vocalizations in infants has a social functions and it is most often responded to by care-givers as interactionally relevant $^{17,18}$. The interactional importance of non-verbal vocalizations in people with dementia is less clear, although it is responded to by interactional partners ${ }^{7}$, which is also demonstrated in the present analysis.

It is interesting to note that both the participating researcher and the other elderly participants orient to Anna's non-verbal vocalizations and respond to them in different ways. Sometimes, they treat them as signs of discomfort responding with questions about pain or boredom. In these sequences, the non-verbal vocalizations are shown to be possible to interrupt by initiatives from the other participants (also see Hydén ${ }^{7}, 2011$ ). The fact that it is possible to interrupt the non-verbal vocalizations has obvious clinical implications, since it points to the importance of addressing this seemingly non-social behavior. This finding adds to the knowledge on the effectiveness of communication interventions on agitation in people with dementia ${ }^{29,30}$, stressing the importance of positive and neutral communicative interventions and a dispreference for negative (anger provoking) interventions. 


\section{References}

1. Perkins, L., Withworth, A. \& Lesser, R. (1998). Conversing in dementia: A conversation analytic approach. Journal of Neurolinguistics, 11, 1-2, 33-53.

2. Cohen-Mansfield, J. \& Werner, P. (1994). Verbally disruptive behaviors in elderly persons: A review. In: Vellas, B.J., Albarede, J.L. \& Garry, P.J. (eds) Facts and Research in gerontology (Supplement). Dementia and Cognitive Impairments. New York: Springer, pp 73-81.

3. Cohen-Mansfield, J. \& Werner, P. (1997). Typology of disruptive vocalizations in older persons suffering from dementia. International Journal of Geriatric Psychiatry, 12, 1079-1091.

4. Bourbonnais, A., \& Ducharme, F. (2008). Screaming in elderly persons with dementia. A critical review of the literature. Dementia, 7, 205-225.

5. Cohen-Mansfield, J. (2000). "Theoretical frameworks for behavioral problems in dementia." Alzheimer's Care Quarterly, 1, 4, 8-21.

6. Sabat, S. R. (2001). Experience of Alzheimer's Disease. Life Through a Tangled Veil. Oxford: Blackwell.

7. Hydén, L. C. (2011). Non-verbal vocalizations, dementia and social interaction. Communication and Medicine.

8. McKhann G, Drachman D, Folstein M, Katzman R, Price D, Stadlan EM. (1984). Clinical diagnosis of Alzheimer's disease: report of the NINCDS-ADRDA Work Group under the auspices of Department of Health and Human Services Task Force on Alzheimer's Disease. Neurology.34, 7, 939-44.

9. Hochanadel, G., and Kaplan, E. (1984). Neuropsychology of normal aging. In Albert, M. L. (ed.), The Neurology of Aging, Oxford University Press, New York, pp. 231244.24.

10. Obler, L.K. \& Albert, M.L. (1981). Language in the senile patient and the elderly aphasic patient. In: M. Sarno (Ed.) Acquired Aphasia, new York: Academic, pp 385398.

11. Potkins, D., Myint, P., Bannister, C., Tadros, G., Chithramohan, R., Swann, A., O’Brien, J., Fossey, J., George, E., Ballard, C. \& Margallo-Lana, M. (2003). Language impairment in dementia: impact on symptoms and care needs in residential homes. International Journal of Geriatric Psychiatry, 18, 1002-1006.

12. Kertesz, A. (2004). Language in Alzheimer's disease. In R. Morris \& J. Becker (Eds.), Cognitive Neuropsychology of Alzheimer's Disease (pp. 197-218). Oxford: Oxford University Press.

13. Morris, R., \& Becker, j. (Eds.). (2004). Cognitive Neuropsychology of Alzheimer's Disease (Second edition ed.). Oxford: Oxford University Press.

14. Rohrer, J.D., Warren, J.D. \& Rossor, M.N. (2009). Abnormal laughter-like vocalizations replacing speech in primary progressive aphasia. Journal of the Neurological Sciences, 284, 1-2, 120-123.

15. Nagaratnam, N., Patel, I. \& Whelan, C. (2003). Screaming, shrieking and muttering: the noise-makers amongst dementia patients. Archives of Gerontological Geriatrics, 36, 247-258.

16. Ryan, D.P., Tainish, S.M.M., Kolodny, V., Lendrum, B.L. \& Fisher, R.H. (1988). Noise-making amongst the elderly in long-term care. Gerontologist, 28, 369-371. 
17. Goldstein, M.H. \& West, M.J. (1999). Consistent responses of mothers to prelinguistic infants: The effect of prelinguistic repertoire size. Journal of Comparative Psychology, $113,52-58$.

18. Goldstein, M.H., King, A.P. \& West, M.J. (2003). Social interaction shapes babbling: Testing parallels between birdsong and speech. Proceedings of the national Academy of Sciences, 100, 8030-8035.

19. Davis, B.L., MacNeilage, P.F., Maytear, C.L. \& Powell, J.K. (2000). Prosodic correlates of stress in babbling: An acoustical study. Child Development, 71, 5, 12581270.

20. Snowdon, C.T. \& Hausberger, M. (1997). (Eds.) Social influence on vocal development. Cambridge: Cambridge University Press.

21. Vihman, M. M. (1996). Phonological development: the origins of language in the child. Oxford: Blackwell.

22. Cohen-Mansfield, J. \& Werner, P., Hammersmith, K. \& Newman, J.D. (2003). Acoustic properties of vocally disruptive behaviors in the nursing home. Gerontology, 49, 161-167.

23. Örulv, L., \& Hydén, L. C. (2006). Confabulation: Sense-making, self-making and world-making in dementia. Discourse Studies, 8, 647-673.

24. Boersma P. \& Weenink, D. (2009). Praat: doing phonetics by computer (Version 5.1.05) [Windows xp]. Retrieved May 1, 2009, from http://www.praat.org/

25. Hamilton, H.E. (1994). Conversations with an Alzheimer's patient. Cambridge: Cambridge University Press.

26. Wells, B. \& Local. J. (1993). The sense of an ending: A case of prosodic delay. Clinical Linguistics and Phonetics, 7, 1, 59-73.

27. Wells, B. \& Local, J. (2009). Prosody as an interactional resource: A clinical linguistic perspective. International Journal of Speech-Language Pathology, 11, 4, 321-325.

28. Hydén, L.C. (2008). Broken and vicarious voices in narratives. In: L.C. Hydén \& J. brockmeier (eds.). Health, Culture and Illness: Broken Narratives, pp36-53. New York: Routeledge

29. McGilton, K.S., Boscart, V., Fox, M., Sidani, S., Rochon, E. \& Sorin-Peters, R. (2009). A systematic review of the effectiveness of communication interventions for health care providers caring for patients in residential care settings. Worldviews on EvidenceBased Nursing,6, 3, 149-159.

30. Vasse, E., Vernooij-Dassen, M., Spijker, A., Rikkert, M.O. \& Koopmans, R. (2010). A systematic review of communication strategies for people with dementia in residential and nursing homes. International Psychogeriatrics, 22, 2, 189-200. 